Journal de la Société des Océanistes

\section{Journal de la Société des Océanistes}

147 | 2018

La Kanaky Nouvelle-Calédonie a rendez-vous avec I'histoire

\title{
Compte rendu de L'accord de Nouméa pour tous par Hamid Mokaddem
}

Isabelle Leblic

\section{OpenEdition}

\section{Journals}

Édition électronique

URL : https://journals.openedition.org/jso/9694

DOI : $10.4000 /$ jso.9694

ISSN : $1760-7256$

Éditeur

Société des océanistes

Édition imprimée

Date de publication : 15 décembre 2018

Pagination : 595-596

ISBN : 978-2-85430-136-6

ISSN : 0300-953x

Référence électronique

Isabelle Leblic, "Compte rendu de L'accord de Nouméa pour tous par Hamid Mokaddem », Journal de la Société des Océanistes [En ligne], 147 | 2018, mis en ligne le 15 décembre 2018, consulté le 27 septembre 2021. URL : http://journals.openedition.org/jso/9694; DOI : https://doi.org/10.4000/jso. 9694

Ce document a été généré automatiquement le 27 septembre 2021.

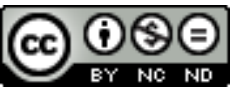

Journal de la société des océanistes est mis à disposition selon les termes de la Licence Creative Commons Attribution - Pas d'Utilisation Commerciale - Pas de Modification 4.0 International. 


\title{
Compte rendu de L'accord de Nouméa pour tous par Hamid Mokaddem
}

\author{
Isabelle Leblic
}

\section{RÉFÉRENCE}

MOKADDEM Hamid, 2012. L'accord de Nouméa pour tous, Nouméa, Institut de formation des maîtres de la Nouvelle-Calédonie, publications de l'IFMNC, 87 p., bibliogr.

1 Ce petit livre reprend deux conférences de l'auteur données en 2011 à l'Institut de formation des maîtres de la Nouvelle-Calédonie afin de permettre une meilleure compréhension des organisations politiques et sociales du pays au moment où se joue un destin politique majeur et décisif. Une introduction (pp.11-13) et une conclusion (pp. 77-79) les encadrent. La première présente le cadre de ces prises de paroles, dans ce «"pays du non-dit" [qui] devient celui du "sur-dit" » (p. 12) :

«Les différences des points de vue sur la souveraineté proviennent des divergences d'interprétations de l'accord de Nouméa. Pour essayer d'y voir plus clair, le propose de déplier les sens et les non-sens de l'accord de Nouméa et d'analyser ensuite les conflits du drapeau. » (p. 13)

2 La première conférence (22 avril 2011), consacrée à l'accord de Nouméa (pp 15-34) explique cet accord politique (pp.19-30) et le rôle des différents partenaires que sont l'État, le FLNKS et le RPCR. L'auteur termine ce chapitre par la souveraineté qui est à la fois point d'accord et de discorde. Puis, il examine le corpus de textes juridicopolitiques qui constituent cet accord sur une idée de compromis (p. 31) pour finir sur la séquence d'événements induite par la durée de l'accord, soit les vingt années qui suivent sa signature, rythmées par les cinq élections provinciales (pp. 32-34). Il évoque notamment l'usure du pouvoir qui entraîne de nombreuses «scissions politiques des deux partis hégémoniques, l'UC et le RPCR " (ce dernier donnera : l'Avenir ensemble, le Rassemblement-UMP, calédonie ensemble, le Mouvement pour la diversité et le Rassemblement pour la Calédonie). Quant au FLNKS, il est divisé par des compétitions 
internes, notamment uc et PALIKA pour le leadership du front. Enfin, l'usTKE crée un parti politique, le Parti travailliste. Tout cela sur fond de destin commun proclamé mais pas toujours mis en pratique.

La seconde (29 avril 2011) porte sur l'affaire du drapeau (pp. 35-75), c'est-à-dire tous les conflits à propos de la levée du drapeau kanaky avec le drapeau français sur les édifices publics face aux hypothèses sur le choix d'un drapeau commun : le drapeau FLNKS pour tous ou un autre drapeau? Dans ce chapitre, il revient sur le fait que :

"L'identification à un seul et même "peuple calédonien" est une fiction. La devise de l'uc, "Deux couleurs, un seul peuple" est une utopie; c'est l'impossibilité d'un imaginaire partagé qui rythme de manière récurrente les conflits locaux. » (p. 38)

H. Mokaddem place son analyse dans la théorie des "esplacements» d'Alain Badiou (1982) qu'il définit comme tel :

"J'entends par "esplacements" les inscriptions des sujets ou des collectifs convertis en sujets dans un espace ouvert et fermé à la fois. La conversion des collectifs en sujet est une logique paradoxale : un collectif se convertit en sujet dès lors qu'il devient acteur sujet de son devenir et de ses processus de subjectivation. » (p. 41)

Il prend en exemple le terme Kanaky, qui renvoie à un espace imaginaire, une idée virtuelle, mais qui néanmoins « donne sens aux inscriptions des sujets en tant que [...] kanak mobilisé autour de l'idée de souveraineté, "le pays kanak indépendant" ». Et les Calédoniens, dans le même mouvement, deviennent un collectif par rapport aux Français de France.

6 À visée pédagogique, ce petit livre souhaite rendre accessible à tous les citoyens du pays l'accord de Nouméa dans ses trois dimensions et ceci, à la lumière des polémiques récurrentes qui occupent l'espace politique calédonien. Il n'est pas inutile d'y revenir dans la période actuelle où les citoyens doivent se prononcer, tel que prévu par l'accord de Nouméa, sur l'avenir institutionnel de la Nouvelle-Calédonie : pleine souveraineté et indépendance ou pas! Donc à lire et relire sans modération.

\section{BIBLIOGRAPHIE}

BADIOU Alain, (1982). Théorie du sujet, Paris, Seuil, coll. L'ordre philosophique. 